\title{
Raderdieren uit het plankton der Amsterdamsche grachten
}

\author{
DOOR \\ Dr. N. WIBAUT-ISEBREE MOENS \\ (met een kaart)
}

\section{INLEIDING}

Het Amsterdamsche grachtencomplex vormt een onderdeel van Amstellands boezem en kan daarvan geheel worden afgesloten. Een reeks van sluizen kan de grachten afsluiten van het IJ-Noordzeekanaal; de afscheiding met het hoofdgedeelte van Amstellands boezem, den Amstel geschiedt door de Amstelsluizen en sluizen in de Stadhouderskade, n.l. de toldeur onder het Leidscheplein en de sluis bij het Weteringhek. Ook met Rijnlands boezem is gedeeltelijk rechtstreeks langs Schinkel en Kostverlorenvaart door de sluizen in de Kostverlorenvaart, gedeeltelijk indirect langs de Ossendorper Binnenpolder communicatie mogelijk. Tegenover den samenhang met Amstellands boezem echter is die met Rijnlands ondergeschikt, daar als regel Rijnland lager staat dan het Stadsgrachtengebied, en menging van het water slechts door het scheepsverkeer langs de Kostverlorenvaart, het v. Lennepkanaal en den Schinkel zal plaats hebben. De afwatering. van het Amstelwater is door het soms vrij aanzienlijke verval van veel meer beteekenis. Verder bestaat er een kunstmatige verbinding met de Zuiderzee langs de 9. syphonkokers, die bij Zeeburg in het Merwedekanaal liggen en waardoor bij voldoend verval tussehen Zuiderzee en het grachtennet water kan worden in- of uitgelaten. Het Zuiderzeewater kan langs dezen weg als spuiwater worden gebruikt en als regel laat men. dagelijks in den nacht een vrij aanzienlijke hoeveelheid zeewater binnen. Het IJ-Noordzeekanaal staat als regel lager dan de stadsgrachten en meestal zal dus slechts stadswater naar dat gebied toevloeien en niet omgekeerd. De totale oppervlakte van het grachtennet bedraagt $\pm 260 \mathrm{H}$.A., de diepte ongeveer $2 \frac{1}{2}$ Meter.

Gedurende drie jaren heb $\mathrm{ik}$ in den regel maandelijks in de Amsterdamsche grachten op vaste punten planktonmonsters verzameld. Dit geschiedde met een tweeledig doel. Allereerst om van dit watergebied de fauna en flora te onderzoeken, waarvan nagenoeg niets bekend was; in de tweede plaats om zoo mogelijk een inzicht te krijgen in de rol van de verschillende micro-organismen in het vervuilings- en zelfreinigingsproces in de stadsgrachten. Sedert het gereedkomen van de groote nieuwe rioleering (1913-1915) vormt het grachtennet niet meer een gelijkvormig geheel, maar er is één gedeelte, n.l. de Oude Stad, waar de toestand bij het oude is gebleven en waar faecaliën en huishoudwater nog in de grachten vloeien en een ander gedeelte n.l. de Nieuwe Stad, alles buiten de Mauritskade-Stadbouderskade-Nasaukade, waarin geen vervuild water meer afvloeit. De beide gebieden hydrobiologisch te vergelijken was mede het doel van dit onderzoek. 
Daar onberispelijk quantitatieve planktonbepalingen tot de uitzonderingen behooren ${ }^{1}$ ) besloot ik mijn monsters althans zóó te nemen en te verzamelen, dat zij onderling vergelijkbaar waren en dat de eventueel gemaakte fouten dan ook voor alle gelijk waren.

In de meeste grachten, althans in de oude stad was het water oppervlakkig veel te vuil om sleepende of horizontaal te kunnen visschen. Aardappelschillen, uien, papier, groentenafval zou het hoofdbestanddeel van het verzamelde „plankton” hebben uitgemaakt. Ook de beweging van de schroef van de motorboot maakt het water voor monsterneming ongeschikt, en om de boot zonder aanzetten van den moter uit te laten loopen daarvoor was op de meeste plaatsen de scheepvaart te druk. Ik besloot daarom met een gewoon horizontaal planktonnet (gaaswijdte $85 \mu$ ) vertikaal te visschen. Het netje werd tot anderhalve meter diepte neergelaten en dan snel opgehaald tot vlak onder het wateroppervlak. Dit werd, om althans iets meer water af te visschen vijfmaal achter elkaar herhaald. Het netje dieper dan anderhalve meter te laten zakken was in de meeste grachten niet mogelijk zonder "bodem"monsters te krijgen. $0 p$ alle plaatsen werd op dezelfde wijze en met hetzelfde netje gevischt, en alle monsters dadelijk in formaline gefixeerd. Deze vangmethode heeft natuurlijk hare bezwaren. Ten eerste ontsnapt het nannoplankton door de mazen van het netje; ten tweede ontvluchten o.a. de meeste cópepoden, daar men deze dieren slechts met een grooter net goed kan vangen; ten derde is de hoeveelheid afgevischt water gering althans veel minder dan zij bij horizontale visscherij in den regel is. Doch in de gegeven omstandigheden was deze methode de meest bruikbare, en daar deze bezwaren voor alle monsters dezelfde zijn, zijn de aldus verzamelde monsters onderling vergelijkbaar. Dit is voor het nagaan van de verspreiding van de met het netje gevangen organismen een eerste vereischte.

Verder droeg ik er zorg voor, dat het monster vanuit de stilliggende boot in het midden van de gracht werd genomen. Het kwam mij voor, dat in een stadsgracht, waarin voortdurend geboomd en gevaren wordt, van een zuivere onderscheiding van een litoraal gebied langs den wallekant en een linmeticum weinig te zien zou zijn, ook al geeft bijv. H. DIEFFEN$\mathbf{B A C H}^{2}$ ) op dat in slooten van 1 Meter een dergelijke invloed van den wal wel waarneembaar is! Mijn bezwaar vlak bij den oever te visschen kwam voort, uit de zichtbare vervuiling door het uit de riolen stroomende water. De invloed van in de gracht geloosd water was bijvoorbeeld op verschillende punten duidelijk waar te nemen aan de temperatuur van het water, zooals uit onderstaand tabelletje blijkt.

Temperatuur van het water aan de oppervlakte in graden Celsius

$\begin{array}{lcc}\text { Datum. } & \text { Entrepôtdok. } & \begin{array}{c}\text { Amstel } \\ \text { b/d Magere brug. }\end{array} \\ 1 \% \text { Maart '16. } & 10^{\circ} & 6^{\circ} \\ 26 \text { April '16. } & 15^{\circ} & 13.5^{\circ} \\ \text { 27 Juni '16. } & 20^{\circ} & 16^{\circ} \\ \text { 2\% Sept, '16. } & 1 \%{ }^{\circ} & 15.5^{\circ} \\ 2 \text { Nov. ' } 16 . & 5.5^{\circ} & 12.5^{\circ} \\ 12 \text { Juni '1\%. } & 26^{\circ} & 25^{\circ} \\ \text { 31 Mei '18. } & 16^{\circ} & 12.5^{\circ} \\ 26 \text { Nov. '18. } & 9^{\circ} & .7 .5^{\circ}\end{array}$

De hoogere temperatuur van het Entrepôtdok-water vergeleken met dat van de overige grachten, waarvoor de Amstel als voorbeeld werd genomen, is te wijten aan het geloosde condenswater van de Electrische Centrale. Alleen 22 Nov. 1916 was de temperatuur van het Entrepôtdok-water lager dan elders. Hoewel hier niet van rechtstreeks belang, moge dit een aanduiding zijn dat men bij grachten steeds rekening moet houden met de mogelijkheid van een invloed van instroomend water.

1) H. Bachmann, Das Phytoplankton des Süsswassers, 1911, p. 23, vooral p. 27.

2) H. Dieffenbach, Biol. Unt. an Rädertieren, Int. Revue d. ges. Hydrobiologie und Hydrographie Bd: IV. Biol. Suppl. 1911-1912, p. 25. 
Uit de volledige analysen van alle planktonmonsters blijkt dat het grachtennet moet verdeeld worden in verschillende gebieden, die op zichzelf min of meer een geheel vormen en wat de planktonsoorten : betreft een eigen karakter hebben. In het eene gebied overwegen meer de marine vormen, in het andere soorten uit het zoete water. De gebieden zijn de volgende:

I. Het van Lennepkwartier tot en met de Nassaukade.

II. Jordaan tot en met de Brouwersgracht.

III. Grachtennet ten westen van den Amstel.

IV. Binnen-Amstel, Rokin, Burgwallen.

V. Markengracht, Houtkoopersburgwal, 0.-Indische kade enz.

VI. Funenkade, Entrepôtdok, grachten ten oosten van den Amstel.

VII. Amstel, Stadhouderskade, Mauritskade.

VIII. Het IJ, Open Haven b/h Centraalstation, Oosterdok.

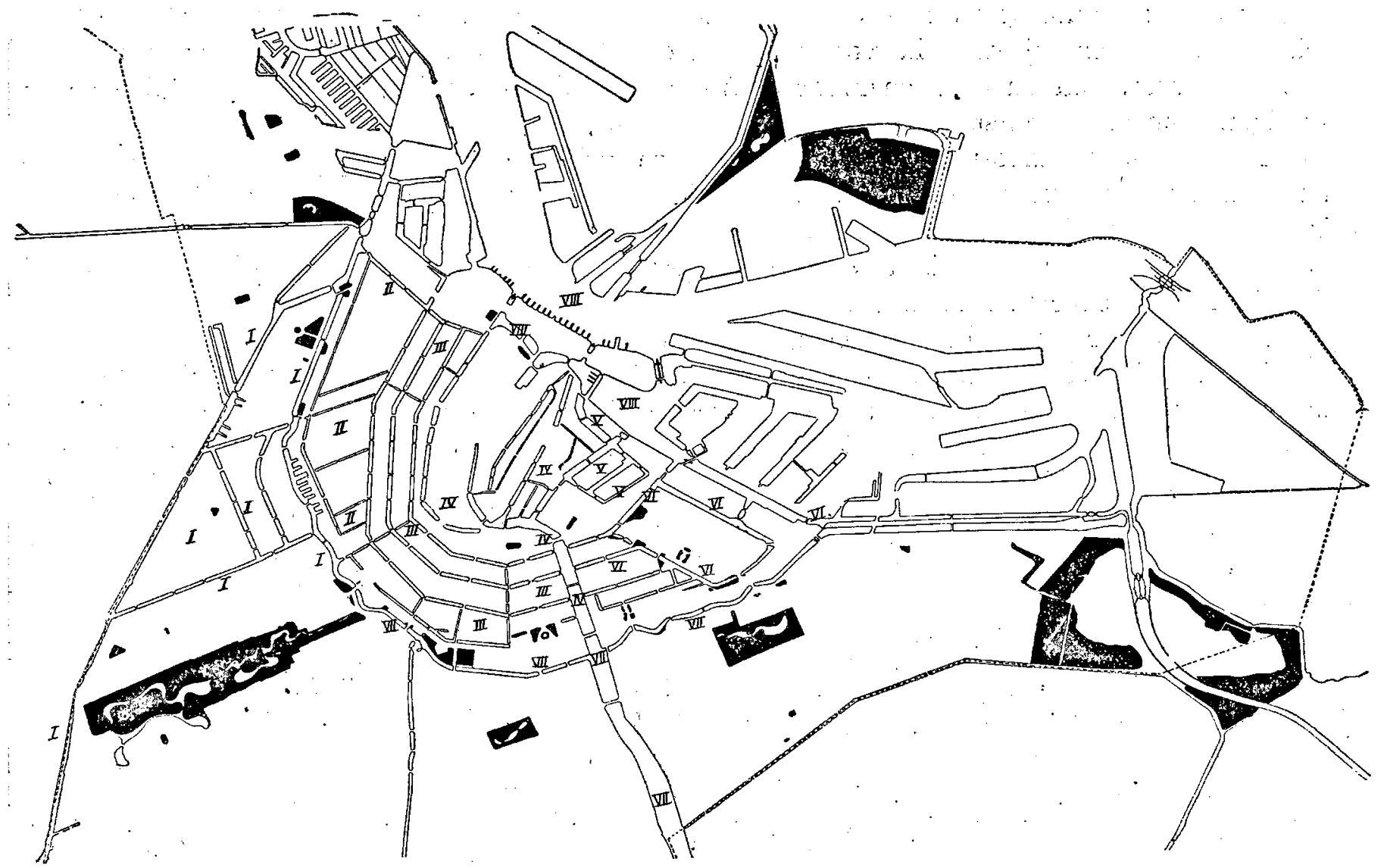

Kaartje van het grachtennet van Amsterdam en van de aangrenzende wateren. I-VIII verschillende gebieden der stadsgrachten (zie tekst). Zwart zijn aangegeven de parken en plantsoenen; die over 't IJ en bij Zeeburg zijn in voorbereiding. ..... grens der gemeente Amsterdam. Schaal 1:50000.

Om verder een beeld te geven van de schommelingen in het chloorgehalte zijn in onderstaande tabel voor elk gebied de in den loop der jaren waargenomen laagste en hoogste cijfers vermeld.

$\begin{array}{clc}\text { Chloorgehalte } & \text { in grammen } & \text { per Liter } \\ \text { Gebied } & \text { minimum } & \text { maximum } \\ \text { I } & 0.5 \text { Jan. } & 4.1 \text { Aug. } \\ \text { II } & 0.5 \text { Jan. } & 3.6 \text { Juni } \\ \text { III } & 0.7 \text { Jan. } & 4.1 \text { Aug. } \\ \text { IV } & 1.5 \text { Nov. } & 4.4 \text { Juli } \\ \text { V } & 2.3 \text { Nov. } & 4.4 \text { Aug. } \\ \text { VI } & 2.3 \text { Dec. } & 4.1 \text { Juni } \\ \text { VII } & 0.6 \text { Mrt. } & 2.5 \text { Juni } \\ \text { VIII } & 1.8 \text { Nov. } & 4.6 \text { Aug. }\end{array}$


Uit de tabel blijken verschillende dingen. Men ziet dat in 't algemeen de laagste chloorcijfers in den winter vallen, de hoogste in de zomermaanden. Deze voor alle grachten geldende regel komt voort uit het feit dat in den winter het Amstelwater zeer overvloedig kan zijn, het ingelaten Zuiderzeewater gering. In den zomer wordt daarentegen veel spuiwater ingelaten en heeft de Amstel een lagen stand. Verder zijn in de gebieden V, VI en VIII de chloorcijfers het geheele jaar hooger dan in aṇdere gebieden.

Ik heb gemeend de raderdieren als geheel uit de gezamelijke planktonmonsters te kunnen behandelen, omdat verschillende soorten bijna steeds het planktonbeeld beheerschen en in alle gebieden, ook in de meest vervuilde, voorkomen. Hieruit mag men verwachten, dat ook in de huishouding van het grachtwater de raderdieren een belangrijke rol spelen en dat het dus van beteekenis is na te gaan, of de soorten in Amsterdam gevonden uit andere deelen van Noord-Holland, zooals den Amstel, den Schinkel, de Zuiderzee, telkens worden aangevoerd; dan wel of zij autochtoon zijn en als ingeburgerde typen van het grachtwater zijn te beschouwen. Hebben zij, wat ik vooronderstel, een belangrijke beteekenis bij de zelfreiniging van het water, dan zal het daarvoor niet onverschillig zijn, wáár de verschillende soorten vandaan komen.

Ik ben zoo gelukkig geweest een opgave te kunnen gebruiken van andere Noord-Hollandsche vindplaatsen van de meeste der in Amsterdam waargenomen soorten. Deze opgave is ontleend aan planktontabellen, welke door Mejuffrouw G. M. DE LiNT, assistente bij het Rijks Instituut voor Biologisch Visscherijonderzoek zijn vervaardigd en die mij door den directeur van genoemd Instituut werd verstrekt.

Bij de onder nader beschreven soorten zal men zien dat het aantal "loricate" soorten de "illoricate" verre overtreft. Dit komt niet omdat zij in het grachtwater niet voorkomen, maar omdat in gefixeerd materiaal de illoricate niet te determineeren zijn. Een aanvulling van uitsluitend naar levend materiaal bepaalde soorten moge dan ook later volgen.

\section{WAARNEMINGEN.}

Anuraea aculeata Ehrbg.

Zeer algemeen, overal, in zoetwater, pelagisch.

Rondom Amsterdam: het geheele jaar en bijna overal talrijk, zoowel in brak- als in zoetwater. Noordzeekanaal, Spaarne, Ringvaart met plassen, Poel bij Amstelveen, Amstel, Abcouder Meer, Gein-Angstel, Merwede-kanaal. In het Abcouder Meer en het Gein klaarblijkelijk voorjaarsvorm.

In Amsterdam: het geheele jaar, $q$ o met eieren in alle gebieden vooral talrijk in I, II, III, VII. - Nog talrijk bij $3 . \%$ gr. Cl. p. L. in de Prinsengracht b/d Runstraat, 6 Juni '16,

Anuraea aculeata curvicornis Gosse.

Verspreid.

In Amsterdam: 's winters, een enkel exemplaar in I en VII.

Anuraea aculeata valga Ehrbg.

Verspreid.

In Amsterdam: voorjaar en zomer, enkele maal 's winters, enkele exemplaren, soms met ei in I, II, III, VI, VII.

Anuraea cochlearis Gosse.

Algemeen verspreid, overal, in zoetwater, pelagisch ${ }^{1}$ ).

Rondom Amsterdam: minder algemeen, doch even verspreid als de vorige, meer in zoet-

1) Volgens Wesenberg-Lund, Studies over de Danske Søers Plankton. 1904. Summary of Contents, p. 32, ,in Denmark in all kinds of water except dung-water (sic!) which it seems to avoid". 
dan in brakwater. Nooit zeer talrijk in het Noordzeekanaal, Spaarne en Ringvaartgebied, overigens samen met de vorige soorten eveneens voorjaarsvorm. In den Amstel.

In Amsterdam: het geheele jaar, niet talrijk, $q O$ met eieren in alle gebieden; vooral in $\mathbf{I}$ en VII.

\section{Anuraea cochlearis tecta Gosse.}

Verspreid, zoetwater; algemeen in brakwater (Wesenberg Lund, 1.c.).

Rondom Amsterdam: met de vorige, doch meer in brakwater naar het schijnt. In het najaar talrijk in het Noordzeekanaal, Spaarne en de Ringvaart, 's voorjaars en zomers vooral in de Poel bij Amstelveen! Zeer zeldzaam in het Abcouder Meer, tamelijk zeldzaam in het Angstel-Gein gebied. Nog niet in den Amstel gevonden.

In Amsterdam, het geheele jaar, meestal zonder eieren in alle gebieden, het talrijkst. hoewel nooit zeer veel in VI, ook VIII, eenmaal vrij veel in de Amstel b/d Munt, 2 Aug. 1916, 4.2 gr. Cl. p. L.

Blijkbaar een vorm, die de voorkeur geeft aan brakwater.

Asplanchna soorten.

In Amsterdam: het geheele jaar, in alle gebieden, dikwijls zeer talrijk.

Brachionus angularis Gosse.

Algemeen, zoetwater, litoraal, 's zomers.

Rondom Amsterdam: de typische vorm in alle jaargetijden, het talrijkst in den zomer, door het geheele gebied verspreid, doch meer in het Noordzeekanaal-Spaarne-Ringvaartcomplex, dan in de zuidelijke boezemwateren. Ook in den Amstel. In het Abcouder Meer slechts zeldzaam.

In Amsterdam: in den zomer, éénmaal in den herfst, in alle gebieden, $q \circ$ met eieren, bijna altijd talrijk, vooral veel in I, VII en IV, en vanuit deze gebieden waarschijnlijk telkens weer aangevoerd in de overige grachten.

\section{Brachionus angularis bidens (Plate).}

Verspreid, zoetwater, waarschijnlijk algemeen, pelagisch, niet 's zomers.

Rondom Amsterdam: eenmaal gevonden in het Alkmaarder Meer.

In Amsterdam: in winter en voorjaar, eenmaal in Juni, enkele exemplaren, soms met ei, vooral in I en II, waarschijnlijk vanuit den Schinkel.

\section{Brachionus bakeri 0. F. Müller.}

Verspreid, soms talrijk, litoraal, 's zomers.

Rondom Amsterdam: over het algemeen zeldzaam, voornamelijk in het NoordzeekanaalSpaarne-Ringvaart-complex, doch alleen in het voorjaar in het Spaarne tamelijk veel. Zeldzaam in den zomer in de Poel, een enkele maal in het Merwedekanaal. Ontbreekt in het Abcouder Meer. Amstel? Schijnt een brakwatervorm te zijn.

In Amsterdam: alleen in April en Juni 1916, talrijk met eieren in V, VI, VII en IV. In Pl. Lijnbaansgracht b/d Muiderpoort 27 Juni '16, in water met 4.1 gr. Cl. p. L.

Blijkbaar een soort, die de voorkeur geeft aan brakwater en in de grachten autochtoon is.

\section{Brachionus bakeri brevispinus Ehrbg.}

Als de vorige soort, litoraal.

In Amsterdam: in zomer en herfst, in alle gebieden; $q$ met eieren en $\sigma^{x} \sigma^{x}$, zeer veel, vooral in I en III, doch ook, hoewel minder veelvuldig, in VI en VIII, niet in VII. Een vorm, die misschien van den Schinkel is binnengekomen, doch zich stellig thuis voelt in ' $t$ brakke water: bijv. zeer talrijk v. Lennepkanaal, 2 Aug. '16, in water met 4.1 gr. Cl. p. Liter! 
Brachionus bakeri cluniorbicularis (Skorik).

In Amsterdam: in April en Juni enkele exemplaren, zelfde monster van Juni, bevatte zeer veel $B r$. bak. brevispinus.

Brachionus mülleri Ehrbg.

Marien en brakwater, algemeen in zeewater, litoraal.

In Amsterdam: alleen in den zomer, met eieren, in alle gebieden, bijna altijd talrijk, zonder voorkeur voor een bepaald gebied, echt grachttype, niet talrijker wordend naar de Zuiderzeekant toe.

\section{Brachionus pala Ehrbg.}

Zeer verspreid, soms zeer talrijk, semipelagisch.

Rondom Amsterdam: evenals Brach. angularis, doch talrịker. In het NoordzeekanaalSpaarne-Ringvaart-complex en in het Merwede-kanaal naast den typischen vorm en nog iets veelvuldiger forma amphiceros (Ehrbg.); in Poel, Abcouder Meer en Gein alleen de typische vorm! Nog niet in den Amstel gevonden.

In Amsterdam: het geheele jaar, in alle gebieden, 우 0 met eieren, ook $\sigma^{7} \sigma^{\gamma}$ doch zeer talrijk in I en misschien vandaar in de overige grachten, ook zeer talrijk in de Nieuwe Vaart, 26 April '16, in water met 2.8 gr. Cl. p. L. - Grachttype?

Brachionus pala amphiceros Ehrbg.

Als pala, pelagisch.

Rondom Amsterdam: zie voorgaande soort.

In Amsterdam: alleen in voorjaar en zomer, zeer talrijk, in alle gebieden behalve $\mathrm{V}$, 오우 met eieren, $\sigma^{\top} \sigma^{\top}$, zeer veelvuldig in I en VII, doch bijv. ook buitengewoon veel 31 Mei 1918 Funenkade, Cl. geh.? Waarschijnlijk wel een grachttype.

Brachionus pala dorcas Gosse.

Zeldzaam, steeds naast pala en amphiceros.

In Amsterdam: in Dec: '15, Jan. Maart en Juni '16, enkele exemplaren met eieren, naast pala en amphiceros, in I, II, III, VI en VII.

Branchionus urceolaris 0. F. Müller.

Meestal algemeen, litoraal en tusschen planten, in grootere watergebieden ontbrekend.

Rondom Amsterdam: minder algemeen verspreid en minder talrijk dan Br. angularis en pala. Veelvuldig alleen in het Spaarne, van voor- tot najaar en, des zomers in het Noordzeekanaal c. a. Zeldzaam in de Poel, de Amstel, het Abcouder Meer en het Gein, meestal alleen in het voorjaar.

In Amsterdam: Mei tot en met September, eenmaal in Januari, in alle gebieden behalve $\mathrm{V}$, 우 met eieren, $\sigma^{\top} \sigma^{\top}$, meestal zeer talrijk, vooral in I maar ook in VIII, bijv. buitengewoon veel op 2 Aug. 1916 in het zwembassin Dijksgracht, in water met $4.5 \mathrm{gr}$. Cl. p. L.; grachttype, dat in het brakwater zéér thuis is.

Notholca acuminata Ehrbg.

Verspreid, vooral talrijk in den winter, pelagisch.

Rondom Amsterdam: overal zeldzaam, komt in het Noordzeekanaal en Spaarne alleen in voorjaar en winter voor, in het Abcouder Meer en het Gein ook in het najaar. 's Winters in den Amstel. Schijnt in de Poel te ontbreken!

In Amsterdam: in winter en voorjaar, steeds enkele exemplaren, in alle gebieden behalve $\mathrm{V}$ en VIII. 
Rotifer spp.

Rondom Amsterdam: verschillende soorten van dit pedonische geslacht werden nu en dan in zomer- en najaarsplankton van het Spaarne aangetroffen.

In Amsterdam: Rotifer vulgaris Schrk., in winter en voorjaar in I en waarschijnlijk ook elders (zie opmerking blz. 154).

Pedalion fennicum Lev.

K. M. Levander, Eine neue Pedalion-Art. In: Zoölogische Anzeiger, XV, 1892, p. $402-404$. -_, Zusatz zu meiner Mittheilung über Pedalion fennicum. In: Zoölogische Anzeiger, XVI, 1894 , p. $26-2 \%$.

-_, Beiträge zur Kenntnis der Pedalion-Arten, mit einer Tafel, p.1-33. In: Acta. Soc. pro fauna et flora fennica, 1895.

C. T. Hudson, On Pedalion mira. In: The Quarterly Journal of microscopical science, Vol. XII, $18 \% 2$, N. Ser., p. 333-338, Taf. XIX.

C. T. Hodson und P. H. Gosse, The Rotifera. Vol. II, 1889, p. 131-133, Taf. XXX, fig. 1. Eug. v. Daday, Morphologisch-physiologische Beiträge zur Kenntnis der Hexarthra polyptera Schm. In: Természetrajzi Füzetek, Budapest (= Natural History Magazine, Hungarian Nat. Museum) Vol. X, p. 214-249. Taf. VIII, IX.

P. de Beadchamp, Seconde liste de Rotifères observés en France. In: Bulletin de la Société Zoologique de France, Vol. 31, 1906, p. 148.

Niet genoemd in Brauer Süsswasserfauna, Heft 14, 1912.

Dit zéér eigenaardige, echt pelagische raderdier moet stellig beschouwd worden als een zeldzaamheid. Het wijkt van Pedalion mirum Huds., die zeer verspreid is en ook in ons land op verscheidene plaatsen in zoetwater voorkomt, af door het ontbreken van de beide dorsale uitsteeksels op het achterlijf en door zijn voorliefde voor brakwater. Levander (1892, p. 402) geeft wel bepaaldelijk op, dat het water, waarin in grooten getale deze door hem als nieuw gevonden soort voorkwam, zoet is, maar de ligging van het kleine poeltje 1 Meter boven den zeespiegel en 10 Meter van de kust in een kale granietrots, maakt het niet onmogelijk, dat al was het water op het oogenblik, dat LevaNDER erin niet zout, het toch brakker dagen gekend had. Het water van de Finsche golf heeft op die hoogte een zoutgehalte van $6-7 \%$. Beadchamp geeft deze soort op in een lijst van marine- of brakwatersoorten voor een poeltje de La Nouvelle in Aude in Zuid Frankrijk aan de golf van Lion.

Rondom Amsterdam: zeldzaam. Tot dusverre alleen gevonden in Zijkanaal $C$ van het Noordzeekanaal (Februari 1915), in het Spoorwegbassin te Helder (Mei 191\%) en in het Alkmaarder Meer (April 1918). Brakwater-dier.

In Amsterdam: het eerst gevonden $22 \mathrm{Mei} 1916$ in de Zuiderzee vlak voor de uitmonding van de Syphonkokers bij Zeeburg (Cl. geh. 3.9 gr. p. L.), wijfjes met één ei, sommige met 4 eieren; 31 Mei 1918 in de Funenkade enkele 우, dienzelfden dag in de Stadhouderskade en in den Binnen-Amstel bij de Munt enkele exemplaren, sommige met één ei.

De door mịj en door Mej. De LINr gevonden exempleren wijken alle eenigszins af van de uitvoerige beschrijving van LeVANDER en van diens teekening (Acta Soc. pro fauna et flora fennica, 1895, fig. 2 en 3). Daar teekent en beschrijft hij de beide laterale extremiteiten; de dorsale heeft $\%$, de ventrale 8 borstels. Op blz. 14 zegt hij: „Bei $P$. fennicum ist "der ventrale Seitenanhang mit acht Borsten versehen ( $3+3$ Seitlichen und 2 an der Spitse), "der dorsale dagegen mit nur sieben. Die Zahlen scheinen ziemlich constant zu sein". Bij de exemplaren uit de stadsgrachten en uit de Zuiderzee vind ik zonder uitzondering aan de ventrale en aan de dorsale extremiteiten elk zes borstels; en ook de exemplaren uit het spoorwegbassin in den Helder, die $\cdot \mathrm{ik}$ gelegenheid had te onderzoeken, hebben alle 6 borstels. De grootte van het dier komt overeen met Levander's maten, die voor 't wijfje opgeeft 0,23 mM.; de Amsterdamsche exemplaren hebben precies dezelfde grootte; enkele exemplaren nit den Helder 0,243 mM. - Bij wijfjes, die één ei droegen, vond ik de grootte daarvan 
0,104 mM. lang, 0,085 mM. breed. De grootte der eieren, die ten getale van 4 bij een der wijfjes voorkwamen, bedroeg $0,06 \check{5}$ bij $0,048 \mathrm{mM}$. Beide getallen wijken dus eenigszins af van de opgave van Levander, die voor de kleine, "manlijke" eieren opgeeft 0,03 mM. en voor de groote, vrouwelijke eieren $0,08 \mathrm{mM}$. lang en $0,06 \mathrm{mM}$. breed.

Polyarthra platyptera Ehrbg.

Zeer verspreid, het geheele jaar, pelagisch.

Rondom Amsterdam : door het geheele gebied verspreid in alle jaargetijden, doch talrijk alleen in de Poel, het Abcouder Meer en het Gein, vooral in het voorjaar. Amstel? schijnt meer van zoet-, dan van brakwater te houden.

In Amsterdam: het geheele jaar, in alle gebieden behalve V en VII, dikwijls met eieren, slechts een enkele maal wat talrijker, bijv. 17 Maart 1916 vrij veel in de Stadhouderskade bij Heinekens Brouwerij, in water met 0,7 gr. Cl. p. L.

Synchaeta spp. Zie opmerking blz. 154.

Triarthra longiseta Ehrog.

Algemeen, het geheele jaar, pelagisch.

Rondom Amsterdam: zeer verspreid, het talrijkst in de voor- en najaarsmaanden. In Noordzeekanaal, Spaarne, Ringvaart en Poel gedurende het geheele jaar, in het Amstelgebied, het Abcouder Meer, het Gein en het Merwedekanaal zeldzaam, of geheel afwezig, in zomer en herfst. Amstel? schijnt meer van brak-, dan van zoetwater te houden.

In Amsterdam: het geheele jaar in alle gebieden, meestal met eieren, komt waarschijnlijk zoowel langs den Schinkel als met Amstelwater in de grachten, komt echter ook talrijk voor in VIII, bijv. in het Oosterdok 2 Aug. ' 16 in water met 4,6 gr. Cl. p. Liter. - Telkens met zoetwater aangevoerd schijnt deze soort zich in brakwater zeer thuis te voelen.

\section{GEVOLGTREKKING.}

Zooals uit bovenstaande opgaven blijkt komen raderdieren het geheele jaar en steeds talrijk in het grachtwater voor. Stellig zijn er sommige soorten, die telkens met het Amstelen Schinkelwater worden aangevoerd. Geen enkele komt met het zeewater in de grachten. Ook van Pedalion fennicum en Brachionus mïlleri geloof ik dat niet, want dan zouden deze soorten zeker vroeger door v. BreEmen in de Zuiderzee zijn gevonden. Daarnaast komen een aantal soorten voor die euryhalien, autochtoon en meso- tot polysaproob zijn, raderdieren die geen voorliefde hebben voor een der gebieden, echte brakwater- èn echte vuilwater vormen, die zich plaatselijk zeer sterk kunnen vermenigvuldigen. Onder deze autochtone soorten zou ik ook Ped. fennicum willen rekenen, ook al hebben wij daar niet veel vindplaatsen van. Tot nu toe is Ped. fennicum slechts aan den buitenrand van de stad gevonden en ik durf nog niet te zeggen of hij vervuild water zou kunnen verdragen. Op grond van bovenstaande gegevens meen ik de beide volgende groepen van grachttypen te kunnen onderscheiden:

I. Met het boezemwater aangevoerde soorten:

II. Autochtone-soorten :

Anuraea aculeata. cochlearis.

Brachionus angularis. Polyarthra platyptera. Triathra longiseta.

\author{
Anuraea cochlearis tecta. \\ Brachionus bakeri en bakeri brevispinus. \\ m mülleri. \\ " pala en pala amphiceros. \\ urceolaris.
}

Pedalion fennicum?

Het komt mij niet overbodig voor een lijsje te geven van de soorten die naast de genoemde raderdieren door mij als echte Amsterdamsche grachttypen werden gevonden. 
Onmiddelijk komt uit die tabel naar voren welk een belangrijk aandeel van het plankton de raderdieren vormen. Het is dan ook te verwachten dat zij bij de zelfreiniging van het grachtwater een bepaalde rol zullen vervullen. Welke die is en waarop dus feitelijk de meso- en polysaprobie dezer dieren berust kan slechts uitgemaakt worden door aan levend

\section{Grachttypen.}

Planten.

Bacillaria paradoxa.

Beggiatoa mirabilis (bodem ?).

Coscinodiscus biconicus.

Oscillaria agardhi.

" tenuis.

Scenedesmus quadricauda.

Dieren.

Anuraea aculeata.

" cochlearis.

Asplanchna ssp.
Balanuslarven.

Brachionus angularis.

bakeri.

" bakeri brevispinus.

” mülleri.

" pala.

" pala amphiceros.

urceolaris.

Codonella lacustris.

Difflugia urceolata.

Eurytemora affinis.

( $\rightarrow$ hixundoïdes).

Naupliën.

(Pedalion fennicum).

Triarthra longiseta.

materiaal waar te nemen wat de dieren eten en tegelijk aan het nannoplankton na te gaan, wáár zij in het water hun dagelijksch voedsel vinden. De kennis van het voedsel, dat door het zoöplankton gebruikt wordt, kan aan de namen oligo-, meso-, en polysabroob diepere beteekenis geven. Zonder deze kennis hebben naar mijne meening deze adjectieven slechts een eenzijdige beteekenis en zal men telkens op de bekende lijsten van. KoLkwIrz en Marsson uitzonderingen vinden.

Een dergelijk onderzoek naar het dieet der verschillende zoöplanktonten wordt thans door mij begonnen.

Amsterdam, 18 December 1918. 